Tohoku J. Exp. Med., 2009, 218, 185-191

\title{
Common Polymorphisms in the XPD and hOGGl Genes Are Not Associated with the Risk of Colorectal Cancer in a Polish Population
}

\author{
Tomasz Sliwinski, ${ }^{1}$ Renata Krupa, ${ }^{2}$ Maria Wisniewska-Jarosinska, ${ }^{3}$ \\ Elzbieta Pawlowska, ${ }^{4}$ Justyna Lech, ${ }^{1}$ Jan Chojnacki ${ }^{3}$ and Janusz Blasiak ${ }^{1}$ \\ ${ }^{1}$ Department of Molecular Genetics, University of Lodz, Lodz, Poland \\ ${ }^{2}$ Laboratory of DNA Repair, Department of Molecular Genetics University of Lodz, Lodz, Poland \\ ${ }^{3}$ Department of Gastroenterology and Internal Diseases, Medical University of Lodz, Lodz, Poland \\ ${ }^{4}$ Department of Pediatric Dentistry, Medical University of Lodz, Lodz, Poland
}

\begin{abstract}
Mutations in the DNA repair genes may contribute to the increased risk of cancer, including colorectal cancer. Xeroderma pigmentosum group D (XPD) protein and human homolog of the 8-oxoguanine glycosylase 1 (hOGG1) are involved in nucleotide excision repair and base excision repair, respectively. The XPD and the hOGG1 genes are highly polymorphic, and some of their polymorphisms are associated with several types of cancers. However, there is controversy as to the relationship between their polymorphisms and the risk of colorectal cancer. In the present study, we therefore searched for the association in a Polish population between colorectal cancer and two common polymorphisms: an A $\rightarrow \mathrm{C}$ transversion in the XPD gene that produces a Lys-to-GIn substitution at codon 751 (the Lys $751 \mathrm{GIn}$ polymorphism; rs28365048) and a C $\rightarrow$ G transversion in the hOGG1 gene resulting in a Ser-to-Cys change at codon 326 (the Ser326Cys polymorphism; rs1052133). Genotypes were determined using peripheral blood lymphocytes of 100 colorectal cancer patients and 100 age-, sex- and ethnicity-matched cancer-free controls by PCR and restriction fragment-length polymorphism analysis. We did not find statistically significant association between each polymorphism and the occurrence of colorectal cancer, and did not observe any relationship between each polymorphism and colorectal cancer progression assessed by node metastasis, tumor size and Duke's stage. Moreover, there was no correlation between combined genotypes of the two polymorphisms and colorectal cancer. Therefore, the Lys751GIn polymorphism of the XPD gene and the Ser326Cys polymorphism of the hOGG1 gene are not associated with colorectal cancer in a Polish population. - XPD; hOGG1; colorectal cancer; DNA repair; gene polymorphism.
\end{abstract}

Tohoku J. Exp. Med., 2009, 218 (3), 185-191. (C) 2009 Tohoku University Medical Press

Colorectal cancer belongs to the most frequent malignant tumors. The Polish 5-year survival rate (below 25\%) belongs to the lowest in the world (Regula et al. 2006). Genetic susceptibility to this disease may result from inherited mutations in genes involved in carcinogen metabolism and DNA repair (Mohrenweiser and Jones 1998; Shields and Harris 2000; Goode et al. 2002). DNA repair systems play a critical role in protecting the genome from insults caused by carcinogenic agents, such as those found in tobacco smoke (Hoeijmakers 1993). More than a hundred proteins are implicated in DNA repair, including nucleotide excision repair (NER) and base excision repair (BER) (Yu et al. 1999; Wood et al. 2001). During the past years, an increasing number of DNA repair gene polymorphisms were described and their involvement in the cancer transformation was investigated. For colorectal cancer, the importance of mutations in mismatch repair (MMR) genes has been extensively documented. Less is known about other DNA repair pathways, including NER and BER. Some epidemiologic studies on polymorphisms in genes of these pathways and cancer reported positive association or a lack of any relationship (Abdel-Rahman et al. 2000; Kim et al. 2003; Mort et al. 2003; Kim et al. 2004; Krupa and Blasiak 2004; Stern et al. 2005; Yeh et al. 2005; Farrington et al. 2005; Hansen et al. 2005).

In this study, we investigated polymorphism of the $X P D$ and hOGG1 genes. The XPD protein (Xeroderma pigmentosum group D) is involved in the NER pathway (Lindahl et al. 1997), which recognizes and repairs a wide range of structurally unrelated lesions, such as bulky adducts and thymidine dimers (Flejter et al. 1992; Braithwaite et al. 1999; de Laat et al. 1999). The XPD gene encodes a helicase that is a component of the transcription factor TFIIH (Sung et al. 1993). Mutations in the XPD gene

Received February 16, 2009; revision accepted for publication May 12, 2009. doi: 10.1620/tjem.218.185

Correspondence: Janusz Blasiak, Department of Molecular Genetics, University of Lodz, Banacha 12/16, 90-237 Lodz, Poland.

e-mail: januszb@biol.uni.lodz.pl 
can diminish the activity of TFIIH complexes, increasing the chance of repair defects, transcription disturbances and abnormal responses to apoptosis (Coin et al. 1999). Several polymorphisms in NER genes, including $X P D$ variants, were found to alter DNA repair, although results of some studies are inconsistent (Duell et al. 2000; Khan et al. 2000; Gozukara et al. 2001; Qiao et al. 2002).

Human homolog of the 8-oxoguanine glycosylase 1 (hOGG1) is a protein involved in the BER pathway, which repairs one of the most mutagenic lesions among base modifications, 8-hydroxyguanine (8-oxoG). 8-oxoG may basepair with adenine, leading to $\mathrm{G}: \mathrm{C} \rightarrow \mathrm{T}: \mathrm{A}$ transversion in repair-deficient cells (Shinmura and Yokota 2001). At least 20 validated sequence variants of the hOGGl gene have been described to date in the Internet databases. Among those, a $\mathrm{C} \rightarrow \mathrm{G}$ sequence variant leading to an amino acid change from serine to cysteine at codon 326 was studied most frequently. Several in vivo or in vitro studies examined the association between $h O G G l$ genotypes and enzyme activity, though the results of these studies are inconsistent (see Weiss et al. 2005 for review).

Earlier studies have shown that the cancer risks associated with commonly occurring single nucleotide polymorphisms (SNPs) are incremental (Goode et al. 2002; Kang 2003). The Ser326Cys polymorphism of the hOGG1 gene was associated with an increased risk of lung, esophagus, and prostate cancer (Goode et al. 2002; Weiss et al. 2005; Hung et al. 2005), while several SNPs of XPD were linked with skin, breast and lung cancer (Benhamou and Sarasin 2005; Manuguerra et al. 2006). In studies that explored potential interactions with environmental factors, cancer risk for the genotypes of the hOGGl gene depending on exposure, especially for colon cancer (see Weis et al. 2005 for review). Therefore, the cancer risk associated with the genotypes of the Ser326Cys polymorphism may be modulated by the location and/or population of the study. This prompted us to search for an association between colorectal cancer occurrence and progression and variants of the XPD and hOGGl genes in a Polish population. We investigated an $\mathrm{A} \rightarrow \mathrm{C}$ transversion in the $X P D$ gene producing a Lys $\rightarrow$ Gln substitution at codon 751 (the Lys751Gln polymorphism; rs28365048) and a C $\rightarrow$ G transversion in the hOGGl gene resulting in a Ser $\rightarrow$ Cys change at codon 326 (the Ser326Cys polymorphism; rs1052133), located on the chromosome 19 and 3, respectively.

\section{Materials and Methods}

Patients

Blood samples were obtained from 100 patients (36 men and 64 women, median age 65 , quartiles: 57,75 years) with CRC treated during the study periods (2000-2001 and 2006-2007) at The Medical University of Lodz, Department of Gastroenterology and Internal Diseases. Incidental patients consist of $90 \%$ of studied population. $10 \%$ were prevalent. Not all patients were included (15\%). Lost patients were similar to those included regarding demographic and tumor characteristics. All patients had histologically confirmed
Table 1. Clinicopathological characteristics of colorectal cancer patients.

\begin{tabular}{lc}
\hline \multicolumn{1}{c}{ Clinical characteristic } & $\begin{array}{c}\text { Patients number } \\
(n=100)\end{array}$ \\
\hline Advanced adenocarcinoma of the colon & 100 \\
Duke's stage & \\
Stage A & 30 \\
Stage B & 35 \\
Stage C & 27 \\
Stage D & 8 \\
Tumor size grade & \\
T1 & 0 \\
T2 & 42 \\
T3 & 54 \\
T4 & 4 \\
Lymph node status & \\
N0 & \\
N1 & 62 \\
N2 & 14 \\
N3 & 16 \\
N4 & 6 \\
&
\end{tabular}

advanced adenocarcinoma of the colon (Table 1). A hundred histologically confirmed cancer-free, sex-, and ethnicity-matched control individuals were selected in the same hospital. They were hospitalized due to gastric symptoms. All invited controls have expressed the wish to participate in our study. All patients as well as controls were Caucasian. Samples were obtained under consideration of all ethical and legal requirements.

\section{Genotype determination}

Genomic DNA was prepared using the guanidine-isothiocyanate method (Lippke et al. 1987). PCR and restriction fragments length polymorphism analysis was employed to determine the genotypes of the Lys751Gln and Ser326Cys polymorphisms. Each $20 \mu 1$ of the PCR reaction contained $10 \mathrm{ng}$ genomic DNA, 1.25 U Taq polymerase (InGen - TERPOL, Sieradz, Poland) in $1 \times$ PCR buffer ( $100 \mathrm{mM}$ Tris$\mathrm{HCl}, \mathrm{pH} 8.3,500 \mathrm{mM} \mathrm{KCl}, 11 \mathrm{mM} \mathrm{MgCl} 2,0.1 \%$ gelatin), $1.5 \mathrm{mM}$ $\mathrm{MgCl}_{2}, 50 \mathrm{mM}$ dNTPs, and $250 \mathrm{nM}$ each primer. Thermal cycling conditions were as follows: initial denaturation step at $95^{\circ} \mathrm{C}$ for, 30 cycles at $95^{\circ} \mathrm{C}$ for $30 \mathrm{sec}$ and $30 \mathrm{sec}$ at the $60^{\circ} \mathrm{C}$ annealing temperature, and at $72^{\circ} \mathrm{C}$ for $1 \mathrm{~min}$. The final extension was performed at $72^{\circ} \mathrm{C}$ for $7 \mathrm{~min}$. The PCR was carried out in a MJ Research, INC thermal cycler, model PTC-100 (Waltham, MA, USA). The Lys751Gln polymorphism for XPD was determined using the following primers (Institute of Biochemistry and Biophysics, Warsaw, Poland): sense, 5'- CTGCTCAGCCTGGAGCAGC - $3^{\prime}$ and antisense, 5'- AAGACCTTCTAGCACCACCG-3'. The 161-bp PCR product was digested overnight with $5 \mathrm{U}$ of the restriction enzyme Pst $\mathrm{I}$. The Gln allele was digested into 120 and 41 bp fragments whereas the Lys variant remained intact (Fig. 1). The Ser326Cys polymorphism was determined using the following primers: sense, 5'- GGAAGGTGC TTGGGGAAT-3' and antisense, 5'- ACTGTCACTAGTCTCACC AG-3'. The 200 bp product was digested overnight with $5 \mathrm{U}$ of the 


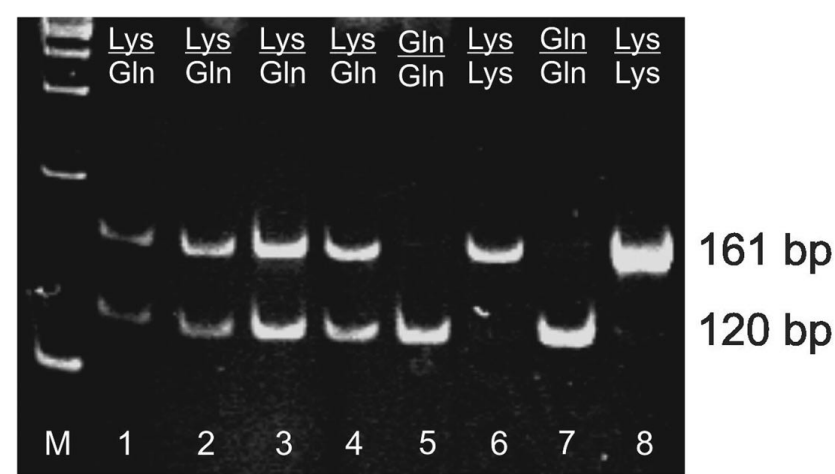

Fig. 1. Representative restriction fragment length polymorphism-polymerase chain reaction (RFLP-PCR) analysis of the Lys751Gln polymorphism of the XPD gene. Lane M, DNA marker $100 \mathrm{bp}$, lane 6 and 8 the Lys751Lys homozygote is not cleaved by Pst enzyme and remains a single 161-bp band, lane 5 and 7 the Gln751Gln homozygote is cleaved by PstI and yields a 120-bp band, lane 1-4 the Lys751Gln heterozygote contains both bands (161 and $120 \mathrm{bp}$ ) following restriction digestion. Digested PCR products were electrophoresed on a $2 \%$ agarose gel containing ethidium bromide. XPD PCR-RFLP band sizes are indicated on the right of panel.

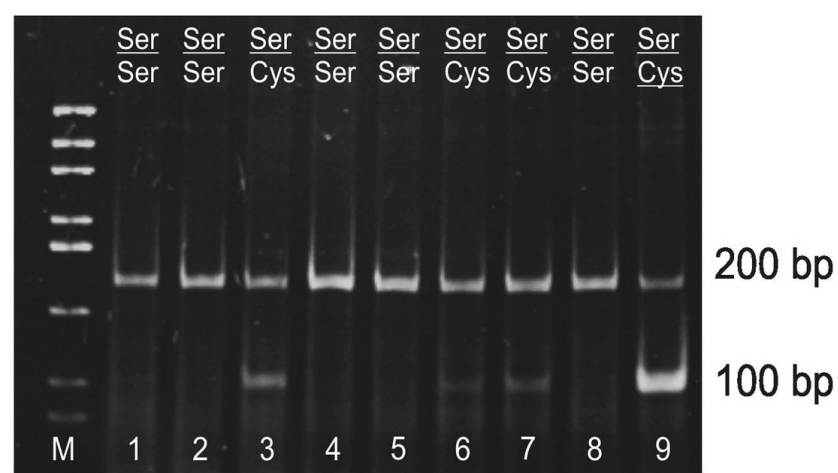

Fig. 2. Representative restriction fragment length polymorphism-polymerase chain reaction (RFLP-PCR) analysis of the Ser326Cys polymorphism of the hOGG1 gene. Lane M, DNA marker pUC19 digested by HaeIII, lane 1, 2, 4, 5 and 8 the Ser326Ser homozygote is not cleaved by Sat I enzyme and remains the single 200-bp band, lane 3, 6, 7 , and 9 the Ser326Cys heterozygote contains all 2 bands (200 and $100 \mathrm{bp}$ ) following restriction digestion. Digested PCR products were electrophoresed on $2 \%$ agarose gel containing ethidium bromide. hOGGl PCR-RFLP band sizes are indicated on the right of panel.

restriction enzyme SatI. The Cys allele was digested into two 100-bp fragments and the Ser was intact (Fig. 2). Restriction fragments were separated on a $8 \%$ polyacrylamide gel stained with ethidium bromide.

\section{Data analysis}

Distribution of genotypes and alleles between groups were tested using chi-square tests. Potential linkage between genotype and cancer was assessed by the logistic regression. Analyses were performed using STATISTICA 6.0 package (Statsoft, Tulsa, OK, USA).

\section{Results}

From the PCR analysis, all the patients and controls were divided according to their genotypes of both polymorphisms. All distributions did not differ significantly $(p>0.05)$ from those predicted by the Hardy-Weinberg equilibrium. We have considered parameters as sex and age in multivariate model. Presented odds ratio's (OR) were adjusted in a logistic regression model that included these parameters. There was no significant association between the genotypes or alleles of both polymorphisms and the occurrence of colorectal cancer (Table 2). However, a tendency of increased risk of association between colorectal cancer occurrence and the Ser326Cys genotype (OR 2.19; 95\% CI 1.22-3.94) and the Lys751Lys genotype (OR 1.76; 95\% CI 1.08-1.86) was observed, although the increase was not statistically significant ( $p>0.05$ for both) (Table 2 ). Likewise, non-significant tendencies were also observed for the Lys allele and the combined Ser326Cys-Lys751Lys genotype (OR 2.23; 95\% CI 1.07-4.67).

Table 3 shows the distribution of genotypes and frequency of alleles in groups of patients with different Duke's stage. Patients were divided into three groups: those in stage $\mathrm{A}$, in stage $\mathrm{B}$ and in stage $\mathrm{C}$ or $\mathrm{D}$. We did not observed any difference between genotype and allele distributions in these groups. The distributions of genotypes and frequency of alleles in patients with lymph node metastasis $(\mathrm{N}+)$ and without it $(\mathrm{N}-)$ lymph node are displayed in Table 3. We did not observed any difference in the distribution of the genotypes of both polymorphisms between these groups. Additionally, there was no difference in distribution of genotypes and frequency of alleles in group of patients with different TNMs.

\section{Discussion}

Although we observed a weak non-significant tendency of a slight increase in OR for some genotypes and alleles of the Lys751Gln polymorphism of the XPD gene and the Ser326Cys polymorphism of the $h O G G 1$ gene, the general conclusion from our results is that both polymorphisms may be not associated with colorectal cancer in a Polish population. We mentioned this tendency, because in those cases ORs are greater than 1 and $95 \%$ CIs do not contain 1, but the differences in number of cases between controls and cancer patients are not significant. However, these results cannot be ignored and they may encourage to continue the study on a larger population.

As we mentioned in the Introduction section, the results on the association between the genotypes of the hOGG1 gene and colorectal cancer are inconsistent and suggest the influence of environmental conditions. Therefore, study performed in different populations should be compared to justify this thesis. Our results indicating a lack of association are in agreement to those performed in a Korean population, despite distinct ethnic differences (Park et al. 2007). It is worth noting that the frequency of the 
Table 2. The Ser326Cys polymorphism of the $h O G G 1$ gene and the Lys751Gln polymorphism of the XPD gene in colorectal cancer patients.

\begin{tabular}{|c|c|c|c|c|}
\hline $\begin{array}{c}\text { Polymorphism } \\
\text { Genotype or Allele }\end{array}$ & Patients $(n=100)$ & Controls $(n=100)$ & OR $(95 \% \mathrm{CI})$ & $p$ \\
\hline \multicolumn{5}{|l|}{ Ser326Cys } \\
\hline Ser326Ser & 52 & 68 & $0.51(0.29-0.91)$ & 0.247 \\
\hline Ser326Cys & 46 & 28 & $2.19(1.22-3.94)$ & 0.073 \\
\hline Сys326Cys & 2 & 4 & $0.49(0.09-2.74)$ & 0.421 \\
\hline $326 \mathrm{Ser}$ & 150 & 164 & $0.66(0.41-1.07)$ & 0.635 \\
\hline 326Cys & 50 & 36 & $1.52(0.94-2.46)$ & 0.310 \\
\hline \multicolumn{5}{|l|}{ Lys751Gln } \\
\hline Lys751Lys & 56 & 42 & $1.76(1.08-1.86)$ & 0.246 \\
\hline Lys751Gln & 33 & 41 & $0.71(0.40-1.26)$ & 0.426 \\
\hline Gln751Gln & 11 & 17 & $0.60(0.27-1.36)$ & 0.426 \\
\hline 751Lys & 146 & 126 & $1.58(1.04-2.41)$ & 0.758 \\
\hline $751 \mathrm{Gln}$ & 54 & 74 & $0.63(0.41-0.96)$ & 0.245 \\
\hline \multicolumn{5}{|l|}{$\begin{array}{l}\text { Genotype combination } \\
\text { Ser326Cys-Lys751Gln }\end{array}$} \\
\hline Ser326Ser - Lys751Lys & 29 & 27 & $1.10(0.60-2.05)$ & 0.813 \\
\hline Ser326Ser-Lys751Gln & 16 & 26 & $0.54(0.27-1.09)$ & 0.101 \\
\hline Ser326Ser-Gln751Gln & 7 & 15 & $0.42(0.17-1.10)$ & 0.105 \\
\hline Ser326Cys-Lys751Lys & 25 & 13 & $2.23(1.07-4.67)$ & 0.074 \\
\hline Ser326Cys-Lys751Gln & 17 & 14 & $1.26(0.59-2.71)$ & 0.616 \\
\hline Ser326Cys-Gln751Gln & 4 & 1 & $4.13(0.45-37.57)$ & 0.185 \\
\hline Cys326Cys-Lys751Lys & 2 & 2 & $1.00(0.14-7.24)$ & 1.000 \\
\hline Cys326Cys-Lys751Gln & 0 & 1 & - & 0.318 \\
\hline Cys326Cys-Gln751Gln & 0 & 1 & - & 0.318 \\
\hline
\end{tabular}

Ser326Cys genotype in the controls in that study was 0.49 , almost 2-fold higher than that reported by us. On the other hand, Moreno et al. (2006) showed that the Ser326Cys polymorphism was associated with an increased risk of colorectal cancer in a Spanish population. The frequency of the Ser326Cys genotype in our controls (0.28) was comparable with that $(0.32)$ reported by Moreno et al. (2006). Distribution data indicate that the frequency of the Lys751Lys genotype in their controls was 0.83 , much higher than that reported by us $(0.42)$ and those stated in other studies (Mort et al. 2003; Skjelbred et al. 2006).

The association of the Lys751Gln polymorphism and the risk of neoplasia was explored for a number of cancers (Goode et al. 2002). Available data on DNA repair gene polymorphisms are not consistent by specific gene or by cancer site, at least in part, because of underpowered studies (Butkiewicz et al. 2001; David-Beabes et al. 2001; Vogel et al. 2001; Hou et al. 2002; Xing et al. 2002; Jeon et al. 2003; Kumar et al. 2003; Liang et al. 2003; Mort et al. 2003; Rybicki et al. 2004). The lack of association between colorectal cancer and the Lys751Gln reported in our study extends the conclusion from studies of Mort et al. (2003),
Yeh et al. (2005) and Skjelbred et al. (2006) on a Polish population. Moreover, Skjelbred et al. (2006) revealed that this polymorphism may predispose to the development of colorectal adenomas or that it may be of importance for arresting the adenoma-carcinoma sequence in the low-risk phase and facilitate the regression of adenomas. This is in contrary to our results, as we did not find any association between this polymorphism and the progression of colorectal cancer. In a Czech population none of the individually analysed polymorphisms of XPD and hOGGl genes was unambiguously associated with colorectal cancer risk (Pardini et al. 2008). Since in general a Czech population is ethnically similar to a Polish population, this may contribute to the thesis about a significant influence of environmental factors on the effect of the genotypes of the $h O G G 1$ gene on colorectal cancer.

Our study has certain limitations. First of all, increasing the number of individuals would increase the power of the study, although there are many reports with similar number of cases (see for instance Yang et al. 2007; Hamano et al. 2008). Second, including family members of the participants would help to distinguish between truly sporadic 
and hereditary cases, as we wanted to focus on the variability of low penetrance genes. Third, the follow-up study could bring more precise answer, as we could not guarantee that the controls would be cancer-free until the end of their lives.

The results obtained in our work indicate that the Lys751Gln polymorphism of the $X P D$ gene and the Ser326Cys polymorphism of the $h O G G 1$ gene are not associated with the occurrence or progression of colorectal cancer in a Polish population.

\section{Acknowledgments}

This work was supported by the grant 505/378 (TS) and 505/376 (RK and JB) from the University of Lodz.

\section{References}

Abdel-Rahman, S.Z., Soliman, A.S., Bondy, M.L., Omar, S., El-Badawy, S.A., Khaled, H.M., Seifeldin, I.A. \& Levin, B. (2000) Inheritance of the 194Trp and the 399Gln variant alleles of the DNA repair gene XRCC1 are associated with increased risk of early-onset colorectal carcinoma in Egypt. Cancer Lett., 159, 79-86.

Benhamou, S. \& Sarasin, A. (2005) ERCC2/XPD gene polymorphisms and lung cancer: a HuGE review. Am. J. Epidemiol., 161, 1-14.

Braithwaite, E., Wu, X. \& Wang, Z. (1999) Repair of DNA lesions: mechanisms and relative repair efficiencies. Mutat. Res., 424, 207-219.

Butkiewicz, D., Rusin, M., Enewold, L., Shields, P.G., Chorazy, M. \& Harris, C.C. (2001) Genetic polymorphisms in DNA repair genes and risk of lung cancer. Carcinogenesis, 22, 593-597.

Coin, F., Bergmann, E., Tremeau-Bravard, A. \& Egly, J.M. (1999) Mutations in XPB and XPD helicases found in xeroderma pigmentosum patients impair the transcription function of TFIIH. EMBO J., 18, 1357-1366.

David-Beabes, G.L., Lunn, R.M. \& London, S.J. (2001) No association between the XPD (Lys751Gln) polymorphism or the XRCC3 (Thr241Met) polymorphism and lung cancer risk. Cancer Epidemiol. Biomarkers Prev., 10, 911-912.

de Laat, W.L., Jaspers, N.G. \& Hoeijmakers, J.H. (1999) Molecular mechanism of nucleotide excision repair. Genes Dev., 13, 768-785.

Duell, E.J., Wiencke, J.K., Cheng, T.J., Varkonyi, A., Zuo, Z.F., Ashok, T.D., Mark, E.J., Wain, J.C., Christiani, D.C. \& Kelsey, K.T. (2000) Polymorphisms in the DNA repair genes XRCC1 and ERCC2 and biomarkers of DNA damage in human blood mononuclear cells. Carcinogenesis, 21, 965-971.

Farrington, S.M., Tenesa, A., Barnetson, R., Wiltshire, A., Prendergast, J., Porteous, M., Campbell, H. \& Dunlop, M.G. (2005) Germline susceptibility to colorectal cancer due to base excision repair gene defects. Am. J. Hum. Genet., 77, 112-119.

Flejter, W.L., McDaniel, L.D., Johns, D., Friedberg, E.C. \& Schultz, R.A. (1992) Correction of xeroderma pigmentosum complementation group D mutant cell phenotypes by chromosome and gene transfer: involvement of the human ERCC2 DNA repair gene. Proc. Natl. Acad. Sci. USA, 89, 261-265.

Goode, E. L., Ulrich, C.M. \& Potter, J.D. (2002) Polymorphisms in DNA repair genes and associations with cancer risk. Cancer Epidemiol. Biomarkers Prev., 11, 1513-1530.

Gozukara, E.M., Khan, S.G., Metin, A., Emmert, S., Busch, D.B., Shahlavi, T., Coleman, D.M., Miller, M., Chinsomboon, N., Stefanini, M. \& Kraemer, K.H. (2001) A stop codon in xeroderma pigmentosum group $\mathrm{C}$ families in Turkey and Italy: 
molecular genetic evidence for a common ancestor. J. Invest. Dermatol., 117, 197-204.

Hamano, T., Matsui, H., Ohtake, N., Nakata, S. \& Suzuki, K. (2008) Polymorphisms of DNA repair genes, XRCC1 and XRCC3, and susceptibility to familial prostate cancer in a Japanese population. Asia Pac. J. Clin. Oncol., 4, 21-26.

Hansen, R., Saebo, M., Skjelbred, C.F., Nexo, B.A., Hagen, P.C., Bock, G., Bowitz Lothe, I.M., Johnson, E., Aase, S., Hansteen, I.L., Vogel, U. \& Kure, E.H. (2005) GPX Pro198Leu and OGG1Ser326Cys polymorphisms and risk of development of colorectal adenomas and colorectal cancer. Cancer Lett., 229, 85-91.

Hoeijmakers, J. H. (1993) Nucleotide excision repair. II: From yeast to mammals. Trends Genet., 9, 211-217.

Hou, S.M., Falt, S., Angelini, S., Yang, K., Nyberg, F., Lambert, B. \& Hemminki, K. (2002) The XPD variant alleles are associated with increased aromatic DNA adduct level and lung cancer risk. Carcinogenesis, 23, 599-603.

Hung, R.J., Hall, J., Brennan, P. \& Boffetta, P. (2005) Genetic polymorphisms in the base excision repair pathway and cancer risk: a HuGE review. Am. J. Epidemiol., 162, 925-942.

Jeon, H.S., Kim, K.M., Park, S.H., Lee, S.Y., Choi, J.E., Lee, G.Y., Kam, S., Park, R.W., Kim, I.S., Kim, C.H., Jung, T.H. \& Park, J.Y. (2003) Relationship between XPG codon 1104 polymorphism and risk of primary lung cancer. Carcinogenesis, 24, 1677-1681.

Kang, D. (2003) Genetic polymorphisms and cancer susceptibility in Korean women. J. Biochem. Mol. Biol., 36, 28-34.

Khan, S.G., Metter, E.J., Tarone, R.E., Bohr, V.A., Grossman, L., Hedayati, M., Bale, S.J., Emmert, S. \& Kraemer, K.H. (2000) A new xeroderma pigmentosum group C poly(AT) insertion/ deletion polymorphism. Carcinogenesis, 21, 1821-1825.

Kim, I.J., Ku, J.L., Kang, H.C., Park, J.H., Yoon, K.A, Shin Y., Park, H.W., Jang, S.G., Lim, S.K., Han, S.Y., Shin, Y.K., Lee, M.R., Jeong, S.Y., Shin, H.R., Lee, J.S., Kim, W.H. \& Park, J.G. (2004) Mutational analysis of OGG1, MYH, MTH1 in FAP, HNPCC and sporadic colorectal cancer patients: R154HOGG1polymorphism is associated with sporadic colorectal cancer patients. Hum. Genet., 115, 498-503.

Kim, J.I., Park, Y.J., Kim, K.H., Kim, J.I., Song, B.J., Lee, M.S., Kim, C.N. \& Chang, S.H. (2003) hOGG1 Ser326Cys polymorphism modifies the significance of the environmental risk factor for colon cancer. World J. Gastroenterol., 9, 956-960.

Krupa, R. \& Blasiak, J. (2004) An association of polymorphism of DNA repair genes XRCC1and XRCC3 with colorectal cancer. J. Exp. Clin. Cancer Res., 23, 285-294.

Kumar, R., Hoglund, L., Zhao, C., Forsti, A., Snellman, E. \& Hemminki, K. (2003) Single nucleotide polymorphisms in the XPG gene: determination of role in DNA repair and breast cancer risk. Int. J. Cancer, 103, 671-675.

Liang, G., Xing, D., Miao, X., Tan, W., Yu, C., Lu, W. \& Lin, D. (2003) Sequence variations in the DNA repair gene XPD and risk of lung cancer in a Chinese population. Int. J. Cancer, 105, 669-673.

Lindahl, T., Karran, P. \& Wood, R.D. (1997) DNA excision repair pathways. Curr. Opin. Genet. Dev., 7, 158-169.

Lippke, J.A., Strzempko, M.N., Raia, F.F., Simon, S.L. \& French, C.K. (1987) Isolation of intact high-molecular-weight DNA by using guanidine isothiocyanate. Appl. Environ. Microbiol., 53, 2588-2589.

Manuguerra, M., Saletta, F., Karagas, M.R., Berwick, M., Veglia, F., Vineis, P. \& Matullo, G. (2006) XRCC3 and XPD/ERCC2 single nucleotide polymorphisms and the risk of cancer: a huge review. Am. J. Epidemiol., 164, 297-302.

Mohrenweiser, H.W. \& Jones, I.M. (1998) Variation in DNA repair is a factor in cancer susceptibility: a paradigm for the promises and perils of individual and population risk estimation? Mutat. Res., 400, 15-24.

Moreno, V., Gemignani, F., Landi, S., Gioia-Patricola, L., Chabrier,
A., Blanco, I., González, S., Guino, E., Capellà, G. \& Canzian, F. (2006) Polymorphisms in genes of nucleotide and base excision repair: risk and prognosis of colorectal cancer. Clin. Cancer Res., 12, 2101-2108.

Mort, R., Mo, L., McEwan, C. \& Melton, D.W. (2003) Lack of involvement of nucleotide excision repair gene polymorphisms in colorectal cancer. Br. J. Cancer, 89, 333-337.

Pardini, B., Naccarati, A., Novotny, J., Smerhovsky, Z., Vodickova, L., Polakova, V., Hanova, M., Slyskova, J., Tulupova, E., Kumar, R., Bortlik, M., Barale, R., Hemminki, K. \& Vodicka P. (2008) DNA repair genetic polymorphisms and risk of colorectal cancer in the Czech Republic. Mutat. Res., 638, 146-153.

Park, H.W., Kim, I.J., Kang, H.C., Jang, S.G., Ahn, S.A., Lee, J.S., Shin, H.R. \& Park, J.G. (2007) The hOGG1 Ser326Cys polymorphism is not associated with colorectal cancer risk. $J$. Epidemiol., 17, 156-160.

Qiao, Y., Spitz, M.R., Shen, H., Guo, Z., Shete, S., Hedayati, M., Grossman, L., Mohrenweiser, H. \& Wei, Q. (2002) Modulation of repair of ultraviolet damage in the host-cell reactivation assay by polymorphic XPC and XPD/ERCC2 genotypes. Carcinogenesis, 23, 295-299.

Regula, J., Zagorowicz, E. \& Butruk, E. (2006) Implementation of a National Colorectal Cancer Screening Program. Current Colorectal Cancer Reports, 2, 25-29.

Rybicki, B.A., Conti, D.V., Moreira, A., Cicek, M., Casey, G. \& Witte, J.S. (2004) DNA repair gene XRCC1 and XPD polymorphisms and risk of prostate cancer. Cancer Epidemiol. Biomarkers Prev., 13, 23-29.

Shields, P.G. \& Harris, C.C. (2000) Cancer risk and low-penetrance susceptibility genes in gene-environment interactions. $J$. Clin. Oncol., 18, 2309-2315.

Shinmura, K. \& Yokota, J. (2001) The OGG1 gene encodes a repair enzyme for oxidatively damaged DNA and is involved in human carcinogenesis. Antioxid. Redox Signal, 3, 597-609.

Skjelbred, C.F., Saebo, M., Wallin, H., Nexo, B.A., Hagen, P.C., Lothe, I.M., Aase, S., Johnson, E., Hansteen, I.L., Vogel, U. \& Kure, E.H. (2006) Polymorphisms of the XRCC1, XRCC3 and XPD genes and risk of colorectal adenoma and carcinoma, in a Norwegian cohort: a case control study. BMC Cancer, $\mathbf{6}$, 67-75.

Stern, M.C., Siegmund, K.D., Corral, R. \& Haile, R.W. (2005) $\mathrm{XRCC} 1$ and XRCC3 polymorphisms and their role as effect modifiers of unsaturated fatty acids and antioxidant intake on colorectal adenomas risk. Cancer Epidemiol. Biomarkers Prev., 14, 609-615.

Sung, P., Bailly, V., Weber, C., Thompson, L.H., Prakash, L. \& Prakash, S. (1993) Human xeroderma pigmentosum group D gene encodes a DNA helicase. Nature, 365, 852-855.

Vogel, U., Hedayati, M., Dybdahl, M., Grossman, L. \& Nexo, B.A. (2001) Polymorphisms of the DNA repair gene XPD: correlations with risk of basal cell carcinoma revisited. Carcinogenesis, 22, 899-904.

Weiss, J.M., Goode, E.L., Ladiges, W.C. \& Ulrich, C.M. (2005) Polymorphic variation in hOGG1 and risk of cancer: a review of the functional and epidemiologic literature. Mol. Carcinog., 42, 127-141.

Wood, R.D., Mitchell, M., Sgouros, J. \& Lindahl, T. (2001) Human DNA repair genes. Science, 291, 1284-1289.

Xing, D., Qi, J., Miao, X., Lu, W., Tan, W. \& Lin, D. (2002) Polymorphisms of DNA repair genes XRCC1 and XPD and their associations with risk of esophageal squamous cell carcinoma in a Chinese population. Int. J. Cancer, 100, 600-605.

Yang, Z.H., Du, B., Wei, Y.S., Zhang, J.H., Zhou, B., Liang, W.B., Jia, J., Zhang, B.L. \& Zhang, L. (2007) Genetic polymorphisms of the DNA repair gene and risk of nasopharyngeal carcinoma. DNA Cell Biol., 26, 491-496.

Yeh, C.C., Sung, F.C., Tang, R., Chang-Chieh, C.R. \& Hsieh, L. 
(2005) Polymorphisms of the XRCC1, XRCC3, \& XPD genes, and colorectal cancer risk: a case-control study in Taiwan. BMC Cancer, $\mathbf{5}, 12$
Yu, Z., Chen, J., Ford, B.N., Brackley, M.E. \& Glickman, B.W. (1999) Human DNA repair systems: an overview. Environ. Mol. Mutagen., 33, 3-20. 